\title{
Review Article; Duodeno-Gastro-Esophageal Reflux Combined and Isolated
}

\author{
${ }^{1}$ Ayman Osman Nasr, ${ }^{2}$ William Robb and ${ }^{2}$ Thomas Neil Walsh \\ ${ }^{1}$ Department of Surgery, Faculty of Medicine, \\ University of Khartoum, P.O. Box 102, Khartoum, Sudan \\ ${ }^{2}$ Department of Surgery, Connolly Hospital, Blanchardstown, Dublin 15, Ireland
}

Received 2012-12-04, Revised 2013-01-09; Accepted 2013-05-08

\begin{abstract}
Barrett's esophagus is the chief risk factor for esophageal adenocarcinoma. Reflux of gastric acid has long been related to the development of esophagitis and Barrett's esophagus, but the role of duodenal contents is controversial. We review the literature on the role of duodenal contents in the development of esophagitis, Barrett's esophagus and adenocarcinoma in addition to the role of acid suppressant therapy in the development or prevention of these changes. A computer-based search of the literature using the terms "Bilirubin, Barrett, Bile Reflux, duodeno-gastric reflux and oesophagus/esophagus" was performed. The role of bile and other constituents of duodenal refluxate were examined. Techniques for identifying nonacid reflux were also reviewed, as were the role of $\mathrm{pH}$, medication and surgery in modulating disease severity. Complicated Barrett's esophagus is associated with increased exposure to gastric and duodenal refluxate. Biological effect of bile acids depends on the conjugation status, the $\mathrm{pH}$ of the milieu and the pKa of bile acids. While Proton Pump Inhibitors reduce the levels of DGER, they also produce changes in gastric and lower esophageal $\mathrm{pH}$ that activate different bile acids at different $\mathrm{pH}$ levels resulting in unexpected injury. Conjugated bile acids are harmful in acidic environment while unconjugated bile acids are harmful at neutral $\mathrm{pH}$ environment. An overlap of toxicity among conjugated and unconjugated bile acids occurs between strongly acidic and neutral $\mathrm{pH}$ levels. Normalisation of gastric and duodenal refluxate should ideally be the goal of treatment.
\end{abstract}

Keywords: Bile Reflux, Acid Reflux, PPI

\section{INTRODUCTION}

The incidence of Gastro-Esophageal Reflux Disease (GERD) increased significantly in the United States between 1970 and 1995 (Devesa et al., 1998). It is now the most common chronic gastro-intestinal disorder and one of the most common conditions presenting to gastroenterologists (Sonnenberg, 2004; Locke, 1997). Approximately $44 \%$ of the adult population in the United States suffer from heartburn on a monthly basis (Locke, 1997; Marshall et al., 1997).

Longstanding GERD is the chief risk factor for the development of intestinal metaplasia (Spechler, 1996; Cameron et al., 1990; Winters et al., 1987), which in turn was attributed to reflux of gastric acid (Balaji et al., 2003), but acid is not the only toxic component of the refluxate. Duodeno-Gastro-Esophageal Reflux (DGER) refers to the reflux of duodenal contents through the stomach into the esophagus. Bile acids, pancreatic enzymes and intestinal enzymes can all result in gastrointestinal mucosal injury in vitro and in vivo (Jolly et al., 2004; Stein et al., 1999; Tibbling et al., 2002). There is adequate information on the toxicity of bile acids to the colonic mucosa (Owen et al., 1984; Turjman and Nair, 1981), hepatocytes (Scholmerich et al., 1984) and gastric mucosa (Gillen et al., 1988a; Gadacz and Zuidema, 1978), but less relating to their toxicity to esophageal mucosa (Gillen et al., 1988a; 1988b; Lagergren et al., 1999; Kauer et al., 1997; 1995a; Attwood et al., 1992). Whereas some authors consider Duodeno-Gastric Reflux (DGR) a physiological event (Schindlbeck et al., 1987), others believe that excessive DGR can damage the gastric

Corresponding Author: Ayman Osman Nasr, Department of Surgery, Faculty of Medicine, University of Khartoum, P.O. Box 102, Khartoum, Sudan 
mucosa (Stern et al., 1984). The evidence that DGER plays a role in the development of both Barrett's esophagus (Iftikhar et al., 1993; Waring et al., 1990) and adenocarcinoma (Miwa et al., 1995) is increasingly convincing. Some of the constituents of DGER can cause injury on their own while the toxicity of others is synergistic with acid at different $\mathrm{pH}$ values.

\subsection{Duodeno-Gastro-Oesophageal Reflux}

\subsubsection{Pathological Reflux}

As the evidence associating Esophageal Acid Exposure (EAE) to mucosal injury, Barrett's esophagus and its complications is so strong. Acid suppression has become the standard of care in the treatment of GERD. However, evidence is accumulating that Non-Acid Refluxate (NAR) plays a major contribution, whether isolated, or acting in synergy with acid reflux in causing esophageal epithelial injury.

Agents other than gastric acid must be involved in the development of esophagitis as symptoms may persist in some despite acid suppression therapy. Esophagitis occurs in patients who have undergone total gastrectomy without biliary diversion and in patients with achlorhydria (Helsingen, 1961; Orlando and Bozymski, 1973; Palmer, 2002; Yumiba et al., 2002; Sandvik and Halvorsen, 1988). Barrett's esophagus has been described after total gastrectomy with esophagojejunostomy (Nishijima et al., 2004). This supports the view that NAR, represented by the reflux of duodenal contents alone, has a role in esophageal mucosal injury. While DGER occur in most patients following partial gastrectomy esophagitis is more prominent in patients with combined reflux (Sears et al., 1995).

In a Swedish study (Lagergren et al., 1999) of 600 patients with cancer of the esophagus or gastric cardia. Esophageal adenocarcinoma was found to be significantly associated with the severity and duration of gastro-esophageal reflux. There was an equally strong association between symptomatic reflux and the risk of adenocarcinoma in patients with Barrett's esophagus and patients without it. They also observed that patients who received medical treatment for reflux had a higher risk for esophageal adenocarcinoma than those who did not (Lagergren et al., 1999).

\subsection{Role of $\mathrm{pH}$ in the Toxicity of Refluxate}

Changes in the $\mathrm{pH}$ of the lower esophageal environment play a crucial role in altering the harmful effect of the refluxate. Kivilaakso et al. (1980) used three parameters to assess mucosal integrity; mucosal potential difference, tissue electrical resistance and tissue permeability to Hydrogen ions $\left(\mathrm{H}^{+}\right)$. They found that conjugated bile acids were largely responsible for mucosal injury in acidic conditions, whereas unconjugated bile acids were more critical when acid was absent. This casts helpful light on the controversy about the role of isolated and combined reflux in inducing lower esophageal injury. Stein et al. (1994a) evaluated 43 normal volunteers and 52 patients with GERD using ambulatory esophageal aspiration and found significantly higher concentrations of refluxed bile acids in patients with GERD $(\mathrm{p}<0.01)$. The percentage time that $\mathrm{pH}$ was above seven and bile acid concentration was elevated was greatest in patients with esophageal strictures and Barrett's esophagus. These findings provide strong evidence that changes in $\mathrm{pH}$ alter the toxicity of bile acids. Other supportive evidence comes from the development of esophagitis among ventilated patients in the intensive care unit on intravenous acid suppression therapy (ranitidine) (Wilmer et al., 1996). The same effect has also been reported for PPIs therapy.

\subsection{Role of Duodenal Reflux in Esophagitis}

The association between duodenal reflux and the severity of esophagitis was examined by Kauer et al. (1995b) who used a fiberoptic probe to detect bile as a marker of duodenal refluxate. They found that patients with erosive esophagitis and Barrett's metaplasia had increased exposure to duodenal juice at a normal esophageal pH. Gillen et al. (1988b) examined the fasting and post-prandial intra-gastric bile acids concentrations in patients with complicated and uncomplicated Barrett's esophagus, esophagitis and normal controls. They found persistently higher concentrations of post-prandial bile acids in patients with complicated Barrett's esophagus. They concluded that duodeno-gastric reflux might be implicated in the pathogenesis of complicated Barrett's esophagus. Vaezi (1995) also studied patients with and without complicated Barrett's esophagus using $24 \mathrm{~h}$ ambulatory $\mathrm{pH}$ monitoring and Bilitec ${ }^{\mathrm{C}} 2000$ monitoring. They found the percentage time that $\mathrm{pH}$ was $<4$ and bilirubin absorbance greater than 0.14 was significantly greater in patients with complicated Barrett's esophagus. They concluded that complications of Barrett's esophagus might be related to synergism between bile and acid rather than the effect of either constituent alone. Acid and duodenal refluxate occur simultaneously in the majority of the reflux episodes and both acid and duodenal refluxate showed a graded increase across the GERD spectrum (Vaezi and Richter, 1996). 


\subsection{Bilirubin Exposure Time and Gradient of Injury}

The observed gradient of exposure to duodenal contents in GERD appears to be independent of race. In a Japanese study the percentage time when bilirubin exposure was greater than 0.15 was significantly higher in those patients with Savary-Miller grades 3 and 4 esophagitis as compared to those with grades 1 and 2 (Osugi et al., 2002). It also appears that the observed relationship between bilirubin exposure and the degree of mucosal injury is independent of age. Orel and Markovic (2003) have recently demonstrated a similar pattern of exposure in paediatric reflux esophagitis. The mean esophageal acid and bilirubin exposure times showed a marked increase from normal volunteers, to GERD patients without esophagitis, to patients with Barrett's esophagus (Marshall et al., 2001).

Stein et al. (1998) studied patients from across the GERD spectrum and found that mean bile exposure time increased exponentially from patients without esophagitis, to those with erosive esophagitis to benign Barrett's metaplasia, being highest in patients with early adenocarcinoma in Barrett's esophagus. Esophageal bilirubin exposure time was highest in patients with high-grade dysplasia or early carcinoma than in Barrett's esophagus alone. Bile primarily refluxed during the post-prandial and supine periods. Pathological bilirubin exposure time ( $>95$ th percentile of normal volunteers) occurred in $11 \%$ of patients with GERD but without esophagitis, in $22 \%$ of patients with GERD and erosive esophagitis, in $55 \%$ of patients with benign Barrett's esophagus and $78.6 \%$ of patients with early adenocarcinoma or high-grade dysplasia in Barrett's esophagus. Both patients with high-grade dysplasia and Barrett's esophagus had pathological bilirubin exposure times.

Oberg et al. (1998) evaluated esophageal exposure to both gastric and duodenal juice in patients with both short and long segments of Barrett's esophagus. The percentage time that $\mathrm{pH}$ was less than 4 increased incrementally across the 4 groups from $3 \%$ in those with no mucosal injury, to $8 \%$ in patients with erosive esophagitis to $9.4 \%$ in patients with short segment Barrett's to $27 \%$ in patients with long segment Barrett's. The percentage time when bilirubin absorbance was greater than 0.2 also increased incrementally across the groups from $0.1 \%$ in those with no mucosal injury, to $4.2 \%$ in those with erosive esophagitis, to $7.9 \%$ in patients with short segment Barrett's and $15.7 \%$ in patients with long segment Barrett's esophagus.
Together these studies suggest that as acid reflux increases so does reflux of duodenal contents. The level of bile reflux closely reflects the levels of acid reflux. This relationship, combined with in-vitro and in-vivo evidence of bile acids toxicity at an acidic $\mathrm{pH}$, gives a compelling suggestion that both acid and bile have a role in generating mucosal injury. The acidic environments in which bile acids are refluxed have a variable effect in accentuating their toxicity.

\subsection{What we have Learned from Animal Reflux Models}

Laboratory animals have been used to study the role of duodenal contents in inducing esophageal mucosal injury. Rats are used more frequently probably because they are easy to handle and faster to breed. The upper gastro-intestinal tract has been surgically altered to maximize, combine or isolate DGER to study different stimuli and effectors (Salo and Kivilaakso, 1982; 1984a; 1984b; Lillemoe et al., 1985).

Different laboratory animals reflux models have been used to study the role of combined and isolated duodenal reflux in lower esophageal carcinogenesis. Both pancreatic and duodenal contents can contribute to the development of adenocarcinoma in the esophagus (Pera et al., 1993). Induced duodeno-esophageal reflux in these models not only increased the frequency of tumour development but also affected the histology of the developed tumours, with a higher proportion of adenocarcinomas (Attwood et al., 1992; Nakama et al., 1998; Miwa et al., 1992a; Fujimura, 1991; Mason et al., 1988; Clemencon et al., 1984). A duodeno-esophageal anastomosis has been frequently used to study combined duodeno/GastroEsophageal Reflux (DER/GER), similar to but more intense than the regular DGER. Theisen et al. (2005) used this model to demonstrate the mutagenic effect of combined reflux through standard big blue mutagenic assay technique. They demonstrated specific mutations similar to those found in p53 mutations of human esophageal adenocarcinoma. Melo et al. (1999) compared DGER to isolated GOR using external carcinogen. DGER was more harmful than GOR with higher percentage of adenocarcinoma.

Nishijima et al. (2004) created three different models for reflux: gastrectomy plus esophago-jejunostomy, gastrectomy plus esophago-duodenostomy and gastrectomy plus Roux-en-Y anastomosis. They concluded that esophago-jejunostomy procedure does not cause regression of Barrett's esophagus but prevents the development of adenocarcinoma. These and other animal studies support the role of duodenal refluxate in 
the metaplasia-dysplasia-carcinoma sequence (Gillen et al., 1988a; Attwood et al., 1992; Miwa et al., 1995; Nishijima et al., 2004; Kivilaakso et al., 1980; Fujimura, 1991; Clark et al., 1994; DeMeester et al., 1987; DeMeester and Ireland, 1997; Di Marco et al., 1990; Fein et al., 2000a; 2000b; Fujikawa et al., 1994; Gerlach et al., 1997; Harmon et al., 1978; Hofmann et al., 1969; Hofmann and Mysels, 1992; Hossain et al., 1988; Isozaki et al., 1995; Kauer and Stein, 2002; Kauer, 2005; Kivilaakso et al., 1981; Segalin et al., 1994; Lillemoe et al., 1983; 1982; Miwa et al., 1992b; Smallwood and Hoffman, 1976; Theisen et al., 2003; Vaezi et al., 1995; Ireland et al., 1996).

Manifold et al. (2000a) studied the role of omeprazole in gastric carcinogenesis induced by duodeno-gastric reflux. They performed a split gastroenterostomy to induce duodeno-gastric reflux and cardiomyotomy to induce gastro-oesophageal reflux in rats. After one year $90 \%$ of rats with surgery and omeprazole developed gastric adenocarcinoma. Although none of the rats developed oesophageal cancer, oesophageal mucosal hyperplasia was more pronounced when compared to surgery alone group.

Moore et al. (2001) performed duodenoesophagostomy on rats to induce duodenal reflux. They treated the study group with a daily intra-peritoneal dose of omeprazole and the control group with normal saline for 6 months. There was no difference in the number of cancers that developed in the two groups.

Using a rodent model of reflux Nasr et al. (2006) recently confirmed that gastric acid suppression in the presence of duodenal refluxate caused increased rates of inflammatory changes, intestinal metaplasia and molecular proliferative activity. The use of PPIs in this model suppressed acute inflammatory changes only, whereas chronic inflammatory changes persisted (Nasr et al., 2006).

\subsection{Pathophysiology of Bile Induced Injury}

The liver conjugates bile acids prior to excretion (Hofmann and Mysels, 1992; Hofmann, 1984; Hofmann and Roda, 1984; Hofmann, 1877; 1977a; 1977b). Conjugated bile acids are soluble at acidic $\mathrm{pH}$. Deconjugation of these acids, however, frequently occurs in the gastrointestinal tract under the action of certain bacteria (Domellof et al., 1980). Upon deconjugation, these bile acids can damage the small intestinal villi (Holt, 1966) and may inhibit the transport of amino acids, sodium and glucose across the jejunal mucosa (Clark et al., 1969; Popesco et al., 1966). Cholecystectomy results in increased intestinal exposure to bile acids which increases the risk of intestinal cancer, a risk that declines down the gastro-intestinal tract with the increasing distance from the common bile duct (Freedman et al., 2001).
Bile acids may diffuse through intact superficial epithelial layers reaching the basal cell layer and directly induce basal cell hyperplasia (Kiroff et al., 1987). They may also accumulate in esophageal epithelium at concentrations up to seven times higher than the initial luminal concentration (Schweitzer et al., 1986). The biological effect of bile acids on esophageal epithelium depends on their conjugation status, the surrounding $\mathrm{pH}$ (Pera et al., 1993) and the pKa of the bile acids (Roda et al., 1995). Unconjugated bile acids promote gastric, duodenal, hepatic and colonic cancers at neutral $\mathrm{pH}$ (Mahmoud et al., 1999), where as conjugated bile acids are more harmful at acidic $\mathrm{pH}$ values (Katz, 2000). Before secretion into the biliary tract, the majority of bile acids are conjugated with taurine or glycine to improve their solubility. As unconjugated bile acids precipitate irreversibly in acidic environment, they cannot cross the mucosal barrier to induce damage. Conjugated bile acids, on the other hand can cross the mucosal barrier and are more toxic in an acidic environment (Richter, 2000). Barrett's esophagus patients have increased conjugated bile acids, but not unconjugated bile acids in their refluxate (Hofmann and Mysels, 1992; Gotley et al., 1988; Nehra et al., 1999).

Taurine-conjugated and glycine-conjugated acids freely soluble in water in a protonated form (Roda et al., 1983). This protonated form still has a lower solubility than that of its corresponding unconjugated derivative. The aqueous solubility of a number of unconjugated bile acids increases as the number of hydroxyl groups increases (Nielsen, 2005). Changes in gastric and lower oesophageal $\mathrm{pH}$ has a profound effect on both the concentration of bile acids and their relative toxicities, as $\mathrm{pH}$ has a major effect on the degree of bile acids' ionisation. The $\mathrm{pKa}$ value of a titratable group (bile acids) is a measure of the free energy difference between the neutral (non-ionized) and charged (ionized) state of the group (Batzri et al., 1991; Schweitzer and Harmon, 1986). Hence the pKa value represents capacity of ionization of a certain bile acid in a defined environment (gastric or oesophageal), which in turn reflects the amount of free $\mathrm{H}^{+}$ions in that environment. This is why the $\mathrm{pKa}$ is dependent on the $\mathrm{pH}$ of that defined environment. Bile acids are ionized at or below their $\mathrm{pKa}$, which prevents them from crossing the mucosal barrier. When the $\mathrm{pH}$ value increases above the $\mathrm{pKa}$ value, bile acids become uncharged which allow them to freely enter the epithelial cells (Roda et al., 1983; Stamp, 2002; Hoffmann et al., 1976; Nair et al., 1970).

\subsection{Toxicity of Bile Acids}

The toxicity of bile acids has been extensively studied and shows a range of individual variation. There is considerable controversy as to which components of 
the refluxate is the most damaging to the esophageal mucosa. The mechanism of mucosal damage by bile acids is poorly understood. Different hypotheses have been proposed.

Bile acids are divided into three main categories (Batzri et al., 1991):

- $\quad$ Free bile acids such as cholic acid, deoxycholic acid and chenodeoxycholic acid, have a pKa's of approximately 7

- Glycine conjugated bile acids such as Glycholic acid, glydexoycholic acid and glychenodexycholic acid have a pKa's of 4.3-5.0

- Taurine conjugated bile acids such as tauricholic acid, taurideoxycholic acid and taurichenodeoxycholic acid have a pKa's of $<2$

Batzri et al. (1991) described bile acids as strong detergents, capable of disrupting lipid bi-layers of the GI tract epithelium and altering its permeability. They can then enter the epithelial cells and become partitioned between the cytoplasm and the lipid membrane compartments, causing disruption of cellular function. Schweitzer et al. (1984) reported a positive correlation between accumulation of bile acids within the mucosa and the degree of mucosal injury. They also found significant disruption of rabbit esophageal mucosa at bile acids concentration well below those required to solubilise phospholipids. This evidence opposes Batzri's concept of bile salt damage being mediated by their detergent properties.

Using net flux of hydrogen ion permeability as a measure of disruption, taurocholate was shown to produce disruption in both extent of mucosal barrier disruption and bile salt absorption in relation to changes in bile salt concentration and in $\mathrm{pH}$ of the rabbit esophageal epithelium (Salo and Kivilaakso, 1984a; 1984b). Demonstrated that both taurocholate and lysolecithin disrupt the trans-mucosal potential difference of rabbit esophageal mucosa in an acidic environment.

\subsection{Toxicity of Pancreatic Secretion}

Pancreatic secretions are also harmful. Pancreatic amylase which, loses its activity at $\mathrm{pH}$ of $\leq 2.0$ in the stomach, normally gains activity again at a $\mathrm{pH}$ of 7.0 in the esophagus (Evander et al., 1987). Trypsin, a pancreatic enzyme similar in action to pepsin, causes damage to the esophageal mucosa by its proteolytic ability. It is most active at a slightly alkaline $\mathrm{pH}$ (7.6-8.0) and loses more than $50 \%$ of its activity in $\mathrm{pH}$ less than 5.0 (Mud et al., 1982). In surgically induced animal models, Trypsin in the oesophageal refluxate may be as high as $12 \mathrm{U} / \mathrm{mL}$ (Imada et al., 1999). The level of Trypsin is low in human gastro-esophageal refluxate, sometimes even undetectable. While it is barely harmful in acidic environment, it is more harmful in acid suppressed situations as post-gastrectomy or during acid blocking therapy (Imada et al., 1999). Its inhibition in postgastrectomy model resulted in both effective prevention and treatment of esophagitis (Imada et al., 1999).

\subsection{Measurement of Reflux}

\subsubsection{Is Alkaline Reflux Indicative of DGER?}

The study of DGER had been hindered by inadequate monitoring systems. The measurement of esophageal $\mathrm{pH}$ as an indication of DGER has a limited role. Pellegrini et al. (1978) using $24 \mathrm{~h} \mathrm{pH}$ monitoring demonstrated the importance of alkaline reflux $(\mathrm{pH} \geq 7)$ as being a marker for DGER. However studies combining bilirubin absorbance and $\mathrm{pH}$ monitoring have shown that the term 'alkaline reflux', as being indicative of duodenal reflux, is a misnomer. Factors such as diet, periodontal disease, the pooling of saliva by strictures and the increased secretion of saliva all contribute to technical inaccuracy of isolated $\mathrm{pH}$ monitoring. Other studies (Mattioli et al., 1990) have suggested that the most common reason for the esophageal $\mathrm{pH}$ to increase to a level higher than 7 is the secretion of bicarbonate by the sub-mucosal glands of the esophagus.

Mattioli et al. (1990) confirmed that 24-h ambulatory esophago-gastric $\mathrm{pH}$ monitoring using a triple $\mathrm{pH}$ probe (placed at the distal esophagus, the fundus and the antrum of the stomach) is a reliable and well-tolerated technique for detecting duodenal reflux. Just et al. (1996) studied the $\mathrm{pH}$ changes associated with DGR. They found that rises in intra-gastric $\mathrm{pH}$ do not predict the presence of bile in normal subjects as DGR does not cause major alkaline shifts of intra gastric $\mathrm{pH}$. They concluded that measuring "alkaline reflux" with ambulatory intra-gastric $\mathrm{pH}$ monitoring alone is an outdated technique. They recommended that Bilitec ${ }^{\circledR}$ 2000 should become the standard technique for the detection of intra-luminal bile.

\subsection{Esophageal Aspiration Studies}

Esophageal aspiration studies have shown that bile acids are found in aspirates of normal volunteers indicating that bile may be present in the stomach and esophagus of normal people without any apparent symptoms aspirates (Kauer et al., 1997). Nevertheless, isolated bile or acid reflux into the esophagus of patients with intact stomach is uncommon (Gotley et al., 1988). 
Nearly half of all patients with reflux symptoms have combined acid and bile reflux (Iftikhar et al., 1993). The combined effect of both gastric and duodenal juices causes severe esophageal mucosal damage in patients with GERD. The vast majority of duodenal reflux injury occurs at a $\mathrm{pH}$ range of 4 to 7 (Stein et al., 1994b), at which an overlap in the activity of bile acids, the major components of duodenal juice, are capable of damaging the esophageal mucosa (Bechi et al., 1993).

\subsection{Measurement of Bile Reflux}

Esophageal aspiration studies utilizing High Performance Liquid Chromatography (HPLC) have been used to identify the most common bile acids in the esophagus. Kauer et al. (1997) detected bile acids in the aspirates of $58 \%$ of normal subjects and $86 \%$ of patients with reflux disease $(\mathrm{p}<0.003)$. They also demonstrated a higher bile acid reflux rate in GERD patients and confirmed that the predominant bile acids refluxed are glycine conjugates. Gotley et al. (1990) using aspiration studies and HPLC identified predominantly conjugated bile acids in $87 \%$ of patients with reflux. The highest levels of bile acids were found in the supine periods and in eleven of 45 patients, levels exceeded $200 \mu \mathrm{moL}^{-1}$. The median conjugated bile acid concentration during the daytime period was significantly lower than that seen at night time and was less than $20 \mu \mathrm{moL}^{-1}$.

Iftikhar et al. (1993) using 18-hour stationary aspiration and HPLC showed that the concentration of bile acids in patients with Barrett's metaplasia was significantly higher than in normal subjects. Taking the 95th percentile of controls as the upper limit of normal, $20 \%$ of patients with esophagitis and $50 \%$ of patients with intestinal metaplasia had an increased exposure to bile acids. The median concentration of total bile acids aspirated in patients with Barrett's esophagus was 1351 $\mu \mathrm{moL}^{-1}$ compared to $465 \mu \mathrm{moL}^{-1}$ in patients with uncomplicated GERD. They concluded that bile acid reflux was implicated in the progression of disease severity. Stein et al. (1995) evaluated 43 normal volunteers and 52 patients with GERD using ambulatory esophageal aspiration and found significantly higher concentrations of refluxed bile acids in patients with GERD $(\mathrm{p}<0.01)$. The percentage time that $\mathrm{pH}$ was $\geq 3$ and bile acid concentration was elevated was greatest in patients with esophageal strictures and Barrett's esophagus.

\subsection{Spectro-photo-metric Bilitec Studies}

Stationary aspiration studies pointed to a graduated level of injury with progressive exposure to bile acids. This has been confirmed in subsequent ambulatory spectro-photo-metric Bilitec studies. The introduction of the Bilitec Probe ${ }^{\mathrm{TM}}$ that detects the presence of bilirubin, the most common bile pigment, in the esophagus as a surrogate marker for duodenal reflux has been a major advance (Shay et al., 2004). It relies on the recognition that increased absorption of light at bilirubin characteristic wavelength $(450 \mathrm{~nm})$ correlates well with the presence of bilirubin and hence bile in the esophagus. It is used as a $24-\mathrm{h}$ ambulatory device, is relatively non-invasive and is independent of the problems associated with $\mathrm{pH}$ monitoring.

Introduction of the Bilitec probe has greatly facilitated investigating the role of DGER in the spectrum of injury associating reflux disease, Barrett's esophagus and their complications. The Bilitec spectrophoto-metric technique was initially validated by in-vitro studies (Marshall et al., 1997). Recent in-vivo study of the sensitivity of the Bilitec probe has been proven to be more reliable with small number of false positive (Kauer et al., 1995a). Introduction of gastric aspirate into the esophageal lumen after in-vitro validation studies of the aspirates has shown that the Bilitec probe may be less sensitive in-vivo in detecting significant reflux episodes (Stein et al., 1995). It appears to underestimate the presence of duodenal juice at acidic $\mathrm{pH}$, (by at least $30 \%$ in acidic medium $\mathrm{pH}<3.5$ ) and requires a modified diet to avoid interference with readings and subsequent false positives (Fein et al., 1996). Despite the variance in validation study findings, the probe is accepted as being sufficiently accurate for ongoing use in clinical studies.

The currently accepted absorbance threshold for esophageal bile reflux is greater than 0.14 (Stipa et al., 1997; Barrett et al., 2000). However there has been criticism of the use of the 0.14 level of absorbance, as the original validation studies continued to show variance and a non-linear progression at an absorbance level of between 0.14 and 0.20 (Sifrim et al., 2004). Kauer et al. (1995a) in their study preferred the higher value of 0.20 on the basis that below this value absorbance was not necessarily due to bilirubin. Other studies have utilized different absorbance thresholds based on their own validation standards. Stein et al. (1998), consequent to their own validation studies, used an absorbance threshold of 0.25 . A similar level was also employed by Okholm et al. (1999) to take account of possible interference in absorbance by dietary intake. The 0.14 level of absorbance is the most widely used in studies to date. Establishing a universally accepted standard level of absorbance is important to avoid generating a large volume of essentially incomparable data.

\subsection{Recent Advances in Measurement}

A newly introduced technology for detecting the type of refluxate in the lower esophagus is the intra-luminal impedance monitoring technique that detects the distribution, composition and clearing of both acid and non-acid esophageal reflux. Using electrodes mounted 
on a standard esophageal $\mathrm{pH}$-monitoring catheter, it allows differentiating between liquid, gas and combined liquid and gas. It detects reflux events regardless of their $\mathrm{pH}$, measuring the amount of time refluxed, material remains in contact with the esophageal, mucosa and the distance above the LES to which the refluxate enters the esophagus (Cabrol et al., 1990; Lujan-Mompean et al., 1993; Lorusso et al., 1990).

Intra-luminal impedance monitoring is considered the only recording method that can achieve high sensitivity for detection of all types of reflux episodes. Its use in combination with pHmetry improves the capacity to detect all reflux events providing the best possible evaluation of the function of the anti-reflux barriers (Jazrawi et al., 1993).

The diagnostic yield of combined $\mathrm{pH}$-impedance monitoring was used to compare the role of non-acid reflux in the pathogenesis of reflux-related symptoms between individuals on or off PPI therapy (Zerbib et al., 2006). More than half $(55 \%)$ the individuals off PPI therapy had positive symptoms association probability of which 31.14 .1 and $20.3 \%$ has occurred during acid reflux, non-acid reflux and mixed reflux (acid and nonacid) respectively, illustrating that their symptoms were mostly relevant to acid and mixed reflux than non-acid reflux. For individuals on PPI therapy, 36.7\% had positive symptoms association probability of which 5, 16.7 and $15 \%$ has occurred during acid reflux, non-acid reflux and mixed reflux respectively, illustrating that their symptoms were mostly relevant to non-acid and mixed reflux.

Combined multi-channel intra-luminal impedance and $\mathrm{pH}$ monitoring (MII-pH) currently represents a change in the reflux testing paradigm with its capacity to detect both liquid and gas reflux and to differentiate between, acid, non-acid and mixed reflux (Tutuian and Castell, 2006). It is becoming the new gold standard method of testing patients with persistent symptoms on acid suppression therapy (Castell and Tutuian, 2007; Bredenoord et al., 2007).

The only downside of MII-pH monitoring is that it cannot confirm or exclude the presence of bilirubin in non-acid and mixed reflux. A down side that renders Spectro-photo-metric Bilitec Study more superior than MII-pH in detecting bile reflux but less useful in detecting gas reflux.

\subsection{Control of Reflux}

\subsubsection{Role of Surgery in the Control of DGER}

During the $1930 \mathrm{sec}$ hiatus hernia was recognised by the medical community as a significant problem. In the $1940 \mathrm{sec}$ it was found to be associated with esophagitis.
It was Philip Allison who was first to associate the symptoms of hiatus hernia to the occurrence of GER. He initiated the modern era of anti-reflux surgery by introducing the Allison repair operation. Ronald Belsey then introduced the partial fundoplication (Belsey repair). Rudolph Nissan performed his fundoplication first in 1937 for a bleeding chronic ulcer of the distal esophagus and again in 1946 for an intra-thoracic stomach. It was until 1954 when he adjusted this operation (fundoplication without resection of the cardia) as a treatment for GERD (Jazrawi et al., 1993; Rothwell et al., 1997).

Stein et al. (1998) compared the role of surgery with medical treatment in controlling esophageal bile reflux. They showed that esophageal bile exposure was reduced by medical treatment $(20 \mathrm{mg}$ of omeprazole twice daily) from $16.2 \%$ of total monitoring time without acid suppression to $8.9 \%$ with acid suppression. Laparoscopic Nissen's fundoplication however normalized esophageal acid and bile exposure in all but 1 of 16 patients who volunteered for follow up reducing esophageal bile exposure from $16.4 \%$ pre-operatively to $2.4 \%$ bilirubin exposure time post operatively. They concluded that Nissen's fundoplication prevents bile reflux into the esophagus which medical acid suppression alone cannot achieve.

Mainie et al. (2006) studied the efficiency of Nissen's fundoplication in the treatment of patients with persistent reflux symptoms documented by (MII-pH) monitoring despite acid suppression therapy. After a mean follow-up of 14 (7-25) months post laparoscopic Nissen's fundoplication, they concluded that patients with positive symptom index resistant to PPIs with documented acid or non-acid reflux by MII-pH monitoring can be treated successfully by laparoscopic Nissen's fundoplication.

Several studies have shown that DGR as well as GER (Freedman et al., 2001) increases after cholecystectomy (Manifold et al., 2000a). It has been suggested that the effect of cholecystectomy is mediated by compromising the LES function (Vela et al., 2001). McDonnell et al. (2002) suggested that the compromise in LES function may be related to elevated levels of cholecystokinin released in patients post cholecystectomy in response to a meal stimulus. The increase of DGR following cholecystectomy may be greater in patients who are symptomatic (Wurm and Caestecker, 2003). In a population-based cohort study of cholecystectomized patients in Sweden between 1965 and 1997 cross-linked with the Swedish Cancer Register, Freedman et al. (2001) found that cholecystectomy was associated with a moderately increased risk of adenocarcinoma of the 
esophagus. They also found that increased intestinal exposure to bile acids after cholecystectomy increases the risk of intestinal cancer, a risk that declines with the increasing distance from the common bile duct. In contrary Manifold et al. (2000b) concluded after performing bilirubin and $\mathrm{pH}$ monitoring on 17 patients with gallstones pre and post cholecystectomy that cholecystectomy does not result in increased DGR or GER.

A malfunctioning gallbladder could behave as an absent gallbladder as in cholecystectomy. Nasr et al. (2006) studied gallbladder function in patients with uncomplicated Barrett's esophagus and esophageal adenocarcinoma. The mean gallbladder ejection fraction decreased progressively from controls to Barrett's to adenocarcinoma and was significantly lower in Barrett's group $(60.9 \% ; \mathrm{p}=0.019)$ and adenocarcinoma group $(47.9 \% ; \quad \mathrm{p}<0.001)$ compared with normal controls (70.9\%). They concluded that gallbladder malfunction increases DGER, exposing the lower esophagus to an altered chemical milieu which, in turn, may have a role in promoting metaplasia-dysplasia-neoplasia sequence in the lower esophageal mucosa.

\subsection{Role of Medication in the Control of DGER}

Burget et al. (1990); Howden and Hunt (1990) and Armstrong et al. (1988) investigated the association between symptoms and acid or Non-Acid Reflux (NAR) in a small subset $(n=5)$ of patients with heartburn and found that heartburn associating NAR decreased dramatically with omeprazole treatment (71 Vs 10\%). This decrease in heartburn was offset by an increase in regurgitation symptoms during acid reflux $(20 \mathrm{Vs}$ $67 \%$ ) during therapy and non-acid reflux (26 Vs $88 \%$ ) during therapy. They concluded that although GERD symptoms are more common with acid reflux, they do occur with NAR.

The last twenty years have seen the evolution of many improved strategies in the medical treatment of GERD and Barrett's esophagus (Chiba, 1997; Stevens et al., 2001). Current medical treatment almost universally involves aggressive acid suppression in order to reduce mucosal injury. They afford resolution of symptoms using lifelong PPIs. Antacids and $\mathrm{H}_{2}$ receptors antagonists no longer have a major role in the treatment of Barrett's oesophagus (Ireland et al., 1996).

Acid suppression has complex effects on the intragastric milieu. Patients on long-term omeprazole have decreased acid secretion and an elevated gastric $\mathrm{pH}$. The resultant overgrowth of the duodenal and gastric microflora (Moore et al., 2001; Wetscher et al., 1999a; 1999b) may facilitate the deconjugation of bile acids in the stomach. This in turn may increase the concentration of dehydroxylated and more toxic unconjugated bile acids (Menges et al., 2001).

Acid suppression therapy can increase gastric $\mathrm{pH}$ from 2 to approximately 6.5 . A $\mathrm{pH} \leq 4.0$ is considered to be the threshold for acidic reflux (Menges et al., 2001). The increase in $\mathrm{pH}$ potentially causes deconjugation and release of the more noxious free bile acids. While numerous studies and meta-analyses have confirmed the superiority of PPIs over $\mathrm{H}_{2}$ RAs for the healing of erosive esophagitis, few studies have examined the role of acid suppression by Proton Pump Inhibitors (PPIs) or $\mathrm{H}_{2}$ Receptors Antagonists $\left(\mathrm{H}_{2} \mathrm{RAs}\right)$ in duodenal reflux-induced esophageal mucosal injury (Champion et al., 1994).

It has been suggested that the introduction of acid suppression therapy correlates with the rapid increase in incidence of esophageal adenocarcinoma in many Western countries. Marshall et al. (1998) reported a progressive increase in the prevalence of esophageal adenocarcinoma in a duodenal reflux animal model as the level of gastric juice in the refluxate was reduced. They concluded that the presence of gastric juice in refluxed duodenal juice protects against the development of esophageal adenocarcinoma. They hypothesised that continuous profound acid suppression therapy may encourage esophageal metaplasia and tumorigenesis in patients with DGER. Several animal models examined the effect of PPI therapy on DGER. Moore et al. (2001) found that the addition of omeprazole did not increase the number of esophageal adenocarcinomas in animals that underwent different forms of surgical reflux to maximize DGER (Netzer et al., 2001). In contrary Nasr et al., 2006) demonstrated that the use of acid suppression therapy in the presence of duodenal refluxate caused increased rates of inflammatory changes, intestinal metaplasia and molecular proliferative activity. They also found that PPIs suppressed acute inflammatory changes only, whereas chronic inflammatory changes persisted which progressed to Barrett's esophagus (Nasr et al., 2006).

Manifold et al. (2000a) analysed the correlation between acid and biliary reflux in patients with esophagitis and patients with Barrett's esophagus by performing 24-h $\mathrm{pH}$ and bile reflux testing utilizing a Bilitec probe. They also examined the effects of PPIs in 20 patients with esophagitis and 23 patients with Barrett's esophagus. Patients off medication that could affect acid secretion or GI motility were studied and compared to patients on PPI therapy. They found that Barrett's patients have increased acid and bile exposure. The median time that bilirubin absorbance was $>0.2$ was $12.8 \%$ in patients with esophagitis and $34.7 \%$ in patients 
with Barrett's esophagus. Within the esophagitis group the median percentage time that Bilirubin absorbance was $>0.2$ was $6.9 \%$ in grades I and II and $18.0 \%$ in grades III and IV. They noticed that the gradient of damage seemed to correlate with the degree of bilirubin exposure. On treatment with a proton pump inhibitor, esophageal bilirubin absorbance decreased from 29.8 to $0.7 \%$ in the Barrett's group and from 21.5 to $0.9 \%$ in patients with esophagitis. They concluded that there was a good correlation between the duration of the esophageal acid/bile exposure and the severity of the pathological change in the esophagus. This study has the advantage of using bile absorbance as indicative of duodenal reflux which is more specific than using only suggestive measures as $\mathrm{pH}$ or MII-pH monitoring which only use non-acid reflux as indicator of duodenal reflux (Wetscher et al., 1999a).

Champion et al. (1994) treated 9 patients (3 with GERD and 6 with Barrett's esophagus) with $40 \mathrm{mg}$ of omeprazole daily and reported a reduction in the percentage time bilirubin absorbance $>0.14$ from 32.8 to 4.7\%. These results showed that omeprazole reduced esophageal bile exposure but not to its normal range. Marshall et al. (2001) examined the effect of omeprazole $20 \mathrm{mg}$ twice daily on duodeno-gastric and gastroesophageal bile reflux in Barrett's esophagus and found that esophageal bilirubin exposure was reduced from a median of 28.9 to $2.4 \%$.

Triadafilopoulos (2006) reported a significant reduction in bile reflux after 28 days of treatment with $40 \mathrm{mg} /$ day of pantoprazole. They also noted that patients who were Helicobacter pylori positive had significantly higher bile reflux times than patients who are H. pylori negative. In contrast, Scarpignato et al. (2006) reported that acid suppression therapy with omeprazole $20 \mathrm{mg}$ twice daily had little effect on the levels of DGR in either patients with Barrett's esophagus, or in healthy controls.

Acid suppression leads to bacterial overgrowth (Ouatu-Lascar and Triadafilopoulos, 1998; Katzka and Castell, 1994; Basu et al., 2002), increase in gastric pH and reflux of toxic unconjugated bile acids known to cause lower oesophageal injury. Bile reflux is more sever in patients with long segment Barrett's oesophagus and aggressive acid suppression therapy reduces both acid and bile reflux. It is unclear why bile reflux should reduce in response to PPIs but Richter et al. (2000) suggest that this is related to the reduced volume of acid in the stomach and so reducing the volume available for reflux into the esophagus. Incomplete acid suppression allows oesophageal exposure to bile acids to continue and may potentiate the ability of bile acids to cause damage, this may be a risk factor for adenocarcinoma. The demonstration that DGER is not affected by omeprazole therapy by some research groups does support the trend of monitoring patients on long term PPIs for signs of oesophageal neoplasia. Different studies showed that symptoms resolution in Barrett's patients on acid suppression does not guarantee acid reflux control.

\section{CONCLUSION}

Bilirubin exposure is increased in a stepwise manner across the spectrum of GERD. Complicated Barrett's esophagus is associated with the highest duodenal refluxate exposure. Bilirubin exposure is merely a surrogate marker for the complex mixture of bile acids and enzymes found in the duodenal refluxate, some of which are more toxic in the presence of acid than alone. The toxicity of specific bile acids and enzymes varies with the $\mathrm{pH}$ of the refluxate. Medical therapy with PPIs appears to significantly reduce the levels of DGER but fail to stop oesophageal mucosal injury. Concern exists that the changes in gastric and lower esophageal $\mathrm{pH}$ created by the use of PPIs medications may activate different bile acids at different $\mathrm{pH}$ levels and result in unexpected injury. It is wise enough to rule out associated bile reflux using a reliable technique such as Bilitec $^{@} 2000$ or MII-pH monitoring in patients with GERD before commencing them on long-term acid suppression therapy. Surgical treatment by Nissen's fundoplication is proven to be an effective treatment in reducing DGER to normal levels. The normalisation of both the reflux of acid and duodenal contents should be the goal of treatment.

\section{REFERENCES}

Armstrong, D., M. Farrell, A. Hanby, G.M. Murphy and R.H. Dowling, 1988. Is the ex vivo rat gastric chamber model suitable for studying the gastrotoxicity of refluxed duodenal contents? Initial results using deoxycholic acid. Clin. Chim. Acta, 178: 313-325. DOI: 10.1016/0009-8981(88)90240-9

Attwood, S.E., T.C. Smyrk, T.R. DeMeester, S.S. Mirvish and H.J. Stein et al., 1992. Duodenoesophageal reflux and the development of esophageal adenocarcinoma in rats. Surgery, 111: 503-510. PMID: 1598670

Balaji, N.S., S.R. DeMeester, K.S. Wickramasinghe, J.A. Hagen and J.H. Peters et al., 2003. Etiology of intestinal metaplasia at the gastroesophageal junction. Surg. Endosc., 17: 43-48. DOI: 10.1007/s00464-002-8944-1 
Barrett, M.W., J.C. Myers, D.I. Watson and G.G. Jamieson, 2000. Detection of bile reflux: In vivo validation of the Bilitec fibreoptic system. Dis. Esophagus, 13: 44-50. DOI: 10.1046/j.14422050.2000.00062.x

Basu, K.K., R. Bale, K.P. West and J.S. de Caestecker, 2002. Persistent acid reflux and symptoms in patients with Barrett's oesophagus on proton-pump inhibitor therapy. Eur. J. Gastroenterol. Hepatol., 14: 1187-1192. PMID: 12439112

Batzri, S., J.W. Harmon, E.J. Schweitzer and R. Toles, 1991. Bile acid accumulation in gastric mucosal cells. Proc. Soc. Exp. Biol. Med., 197: 393-399. PMID: 1871149

Bechi, P., F. Pucciani, F. Baldini, F. Cosi and R. Falciai et al., 1993. Long-term ambulatory enterogastric reflux monitoring. Validation of a new fiberoptic technique. Dig. Dis. Sci., 38: 1297-1306. DOI: 10.1007/BF01296082

Bredenoord, A.J., R. Tutuian, A.J.P.M. Smout and D.O. Castell, 2007. Technology review: Esophageal impedance monitoring. Am. J. Gastroenterol., 102: 187-194. DOI: $10.1111 /$ j.1572-0241.2006.00966.x

Burget, D.W., S.G. Chiverton and R.H. Hunt, 1990. Is there an optimal degree of acid suppression for healing of duodenal ulcers? A model of the relationship between ulcer healing and acid suppression. Gastroenterology, 99: 345-351. PMID: 2142113

Cabrol, J., X. Navarro, J. Simo-Deu and R. Segura, 1990. Evaluation of duodenogastric reflux in gallstone disease before and after simple cholecystectomy. Am. J. Surg., 160: 283-286. DOI: 10.1016/S00029610(06)80024-3

Cameron, A.J., A.R. Zinsmeister, D.J. Ballard and J.A. Carney, 1990. Prevalence of columnar-lined (Barrett's) esophagus. Comparison of populationbased clinical and autopsy findings. Gastroenterology, 99: 918-922. PMID: 2394347

Castell, D. and R. Tutuian, 2007. The changing paradigm of GERD. Curr. Gastroenterol. Reports, 9: 441-442. DOI: $10.1007 /$ s1 1894-007-0056-6

Champion, G., J.E. Richter, M.F. Vaezi, S. Singh and R. Alexander, 1994. Duodenogastroesophageal reflux: Relationship to $\mathrm{pH}$ and importance in Barrett's esophagus. Gastroenterology, 107: 747-754. DOI: 10.1016/0016-5085(94)90123-6

Chiba, N., 1997. Proton pump inhibitors in acute healing and maintenance of erosive or worse esophagitis: A systematic overview. Can. J. Gastroenterol., 11: 66B-73B. PMID: 9347181
Clark, A.G., P.C. Hirom, P. Millburn, R.L. Smith and R.T. Williams, 1969. Reabsorption from the biliary system as a factor influencing the biliary excretion of organic anions. Biochem. J., 115: 62P-62P. PMID: 5360716

Clark, G.W., T.C. Smyrk, S.S. Mirvish, M. Anselmino and Y. Yamashita et al., 1994. Effect of gastroduodenal juice and dietary fat on the development of Barrett's esophagus and esophageal neoplasia: An experimental rat model. Ann. Surg. Oncol., 1: 252-261. DOI: 10.1007/BF02303531

Clemencon, G.H., H.F. Fehr and J. Finger, 1984. The role of bile salts in cysteamine-induced duodenal ulcer in the rat and the ulceroprotective property of lysolecithin. Scand J. Gastroenterol. Suppl., 92: 116120. PMID: 6588495

DeMeester, T.R. and A.P. Ireland, 1997. Gastric pathology as an initiator and potentiator of gastroesophageal reflux disease. Dis. Esophagus, 10: 1-8. PMID: 9079266

DeMeester, T.R., K.H. Fuchs, C.S. Ball, M. Albertucci and T.C. Smyrk et al., 1987. Experimental and clinical results with proximal end-to-end duodenojejunostomy for pathologic duodenogastric reflux. Ann. Surg., 206: 414-426. DOI: 10.1097/00000658-198710000-00003

Devesa, S.S., W.J. Blot and J.F. Fraumeni, 1998. Changing patterns in the incidence of esophageal and gastric carcinoma in the United States. Cancer, 83: 2049-2053. DOI: 10.1002/(SICI)10970142(19981115)83:10<2049::AID-

CNCR1>3.0.CO;2-2

Di Marco, E., J.H. Pierce, S.A. Aaronson and P.P. Di Fiore, 1990. Mechanisms by which EGF receptor and TGF alpha contribute to malignant transformation. Nat. Immun. Cell Growth Regul., 9: 209-221. PMID: 2196461

Domellof, L., B.S. Reddy and J.H. Weisburger, 1980. Microflora and deconjugation of bile acids in alkaline reflux after partial gastrectomy. Am. J. Surg., 140: 291-295. DOI: 10.1016/00029610(80)90024-0

Evander, A., A.G. Little, R.H. Riddell, B. Walther and D.B. Skinner, 1987. Composition of the refluxed material determines the degree of reflux esophagitis in the dog. Gastroenterology, 93: 280-286. PMID: 3596163

Fein, M., K.H. Fuchs, H. Stopper, S. Diem and M. Herderich, 2000a. Duodenogastric reflux and foregut carcinogenesis: Analysis of duodenal juice in a rodent model of cancer. Carcinogenesis, 21: 2079-2084. DOI: 10.1093/carcin/21.11.2079 
Fein, M., K.H. Fuchs, T. Bohrer, S.M. Freys and A. Thiede, 1996. Fiberoptic technique for 24-h bile reflux monitoring. Standards and normal values for gastric monitoring. Dig. Dis. Sci., 41: 216-225. DOI: 10.1007/BF02208607

Fein, M., K.H. Fuchs, T.R. DeMeester, J.H. Peters and D. Wittmann et al., 2000b. Evaluation of the intestinal microflora in the rat model for esophageal adenocarcinoma. Dis. Esophagus, 13: 39-43. DOI: 10.1046/j.1442-2050.2000.00023.x

Freedman, J., W. Ye, E. Naslund and J. Lagergren, 2001. Association between cholecystectomy and adenocarcinoma of the esophagus. Gastroenterology, 121: 548-553. DOI: 10.1053/gast.2001.27217

Fujikawa, H., T. Saijyo, S. Ito and K. Ii, 1994. Studies of experimental model of reflux esophagitis in rats by ligature on both lower portion of duodenum and most of forestomach. Nippon Shokakibyo Gakkai Zasshi, 91: 829-838. PMID: 8170054

Fujimura, T., 1991. Effects of reflux of bile and/or pancreaticoduodenal juice on gastric carcinogenesis in rats. Nippon Geka Gakkai Zasshi, 92: 933-939. PMID: 1944147

Gadacz, T.R. and G.D. Zuidema, 1978. Bile acid composition in patients with and without symptoms of postoperative refulx gastritis. Am. J. Surg., 135: 48-52. DOI: 10.1016/0002-9610(78)90008-9

Gerlach, C., M. Golding, L. Larue, M.R. Alison and J. Gerdes, 1997. Ki-67 immunoexpression is a robust marker of proliferative cells in the rat. Lab Invest., 77: 697-698. PMID: 9426408

Gillen, P., P. Keeling, P.J. Byrne A.B. West and T.P. Hennessy, 1988a. Experimental columnar metaplasia in the canine oesophagus. Br. J. Surg., 75: 113-115. DOI: 10.1002/bjs. 1800750208

Gillen, P., P. Keeling, P.J. Byrne, M. Healy, R.R. O'Moore and T.P. Hennessy, 1988b. Implication of duodenogastric reflux in the pathogenesis of Barrett's oesophagus. Br. J. Surg., 75: 540-543. DOI: $10.1002 /$ bjs. 1800750612

Gotley, D.C., A.P. Morgan and M.J. Cooper, 1988. Bile acid concentrations in the refluxate of patients with reflux oesophagitis. Br. J. Surg., 75: 587-590. DOI: 10.1002/bjs.1800750632

Gotley, D.C., A.P. Morgan and M.J. Cooper, 1990. New technique for analysing conjugated bile acids in gastric juice. J. Clin. Pathol., 43: 924-928. DOI: 10.1136/jcp.43.11.924
Harmon, J.W., T. Doong and T.R. Gadacz, 1978. Bile acids are not equally damaging to the gastric mucosa. Surgery, 84: 79-86. PMID: 26987

Helsingen, N., 1961. Oesophagitis following total gastrectomy. A clinical and experimental study. Acta Chir. Scand. Suppl., 273: 1-21. PMID: 13713207

Hoffmann, D., S.S. Hecht, R.M. Ornaf, E.L. Wynder and T.C. Tso, 1976. Chemical studies on tobacco smoke. XLII. Nitrosonornicotine: Presence in tobacco, formation and carcinogenicity. IARC Sci. Publ., 14: 307-320. PMID: 12092

Hofmann, A.F. and A. Roda, 1984. Physicochemical properties of bile acids and their relationship to biological properties: An overview of the problem. J. Lipid. Res., 25: 1477-1489. PMID: 6397555

Hofmann, A.F. and K.J. Mysels, 1992. Bile acid solubility and precipitation in vitro and in vivo: The role of conjugation, $\mathrm{pH}$ and $\mathrm{Ca} 2+$ ions. J. Lipid Res., 33: 617-626. PMID: 1619357

Hofmann, A.F., 1877. The enterohepatic circulation of bile acids in man. Wis. Med. J., 75: 35-40.

Hofmann, A.F., 1977a. The enterohepatic circulation of conjugated bile acids in healthy man: Quantitative description and functions. Expos. Annu. Biochim. Med., 33: 69-86. PMID: 330215

Hofmann, A.F., 1977b. The enterohepatic circulation of bile acids in man. Clin. Gastroenterol., 6: 3-24. PMID: 330051

Hofmann, A.F., 1984. Chemistry and enterohepatic circulation of bile acids. Hepatology, 4: 4S-14S. DOI: 10.1002/hep.1840040803

Hofmann, A.F., E.H. Mosbach and C.C. Sweeley, 1969. Bile acid composition of bile from germ-free rabbits. Biochim. Biophys. Acta., 176: 204-207. DOI: 10.1016/0005-2760(69)90092-7

Holt, P.R., 1966. Competitive inhibition of intestinal bile salt absorption in the rat. Am. J. Physiol., 210: 635639. PMID: 5933218

Hossain, M.A., D.F. Cottrell, M.A. Camburn and J.R. Campbell, 1988. Gastro-oesophageal reflux in halothane anaesthetized sheep. The effects of feeding and positioning. Vet. Res. Commun., 12: 227-232. DOI: 10.1007/BF00362804

Howden, C.W. and R.H. Hunt, 1990. The relationship between suppression of acidity and gastric ulcer healing rates. Aliment. Pharmacol. Ther, 4: 25-33. DOI: 10.1111/j.1365-2036.1990.tb00445.x

Iftikhar, S.Y., S. Ledingham, R.J. Steele, D.F. Evans and K. Lendrum et al., 1993. Bile reflux in columnarlined Barrett's oesophagus. Ann. R. Coll. Surg. Engl., 75: 411-416. PMID: 8285543 
Imada, T., C. Chen, S. Hatori, M. Shiozawa and Y. Rino, 1999. Effect of trypsin inhibitor on reflux oesophagitis after total gastrectomy in rats. Eur. J. Surg., $\quad 165$ : $1045-1050$. DOI: $10.1080 / 110241599750007874$

Ireland, A.P., J.H. Peters, T.C. Smyrk, T.R. DeMeester and G.W. Clark et al., 1996. Gastric juice protects against the development of esophageal adenocarcinoma in the rat. Ann. Surg., 224: 358370. DOI: $10.1097 / 00000658-199609000-00012$

Isozaki, K., S. Hirota, A. Nakama, J. Miyagawa and Y. Shinomura et al., 1995. Disturbed intestinal movement, bile reflux to the stomach and deficiency of c-kit-expressing cells in $\mathrm{Ws} / \mathrm{Ws}$ mutant rats. Gastroenterology, 109: 456-464. DOI: 10.1016/0016-5085(95)90333-X

Jazrawi, S., T.N. Walsh, P.J. Byrne, A.D. Hill and H. Li et al., 1993. Cholecystectomy and oesophageal reflux: A prospective evaluation. Br. J. Surg., 80: 50-53. DOI: $10.1002 /$ bjs. 1800800119

Jolly, A.J., C.P. Wild and L.J. Hardie, 2004. Acid and bile salts induce DNA damage in human oesophageal cell lines. Mutagenesis, 19: 319-324. DOI: 10.1093/mutage/geh035

Just, R.J., L.P. Leite and D.O. Castell, 1996. Changes in overnight fasting intragastric $\mathrm{pH}$ show poor correlation with duodenogastric bile reflux in normal subjects. Am. J. Gastroenterol., 91: 15671570. PMID: 8759663

Katz, P.O., 2000. Review article: The role of non-acid reflux in gastro-oesophageal reflux disease. Aliment Pharmacol. Ther., 14: 1539-1551. DOI: 10.1046/j.1365-2036.2000.00875.x

Katzka, D.A. and D.O. Castell, 1994. Successful elimination of reflux symptoms does not insure adequate control of acid reflux in patients with Barrett's esophagus. Am. J. Gastroenterol., 89: 989-991.

Kauer, W.K., 2005. Stein HJ. Bile reflux in the constellation of gastroesophageal reflux disease. Thorac. Surg. Clin., 15: 335-340. DOI: 10.1016/j.thorsurg.2005.03.004

Kauer, W.K., J.H. Peters, T.R. DeMeester, A.P. Ireland and C.G. Bremner et al., 1995a. Mixed reflux of gastric and duodenal juices is more harmful to the esophagus than gastric juice alone. The need for surgical therapy re-emphasized. Ann. Surg., 222: 525-531. PMID: 7574932

Kauer, W.K., J.H. Peters, T.R. DeMeester, H. Feussner and A.P. Ireland et al., 1997. Composition and concentration of bile acid reflux into the esophagus of patients with gastroesophageal reflux disease. Surgery, 122: 874-881. DOI: 10.1016/S00396060(97)90327-5
Kauer, W.K., P. Burdiles, A.P. Ireland, G.W. Clark and J.H. Peters et al., 1995b. Does duodenal juice reflux into the esophagus of patients with complicated GERD? Evaluation of a fiberoptic sensor for bilirubin. Am. J. Surg., 169: 98-103. DOI: 10.1016/S0002-9610(99)80116-0

Kauer, W.K.H. and H.J. Stein, 2002. Role of acid and bile in the genesis of Barrett's esophagus. Chest Surg. Clin N. Am., 12: 39-45. DOI: 10.1016/S10523359(03)00064-4

Kiroff, G.K., P.G. Devitt, N.J. DeYoung and G.G. Jamieson, 1987. Bile salt-induced injury of rabbit oesophageal mucosa measured by hydrogen ion disappearance. Aust. N Z J. Surg., 57: 111-117. DOI: $10.1111 /$ j.1445-2197.1987.tb01314.x

Kivilaakso, E., D. Fromm and W. Silen, 1980. Effect of bile salts and related compounds on isolated esophageal mucosa. Surgery, 87: 280-285. PMID: 6767288

Kivilaakso, E., D. Fromm and W. Silen, 1981. Effect of bile salts and related compounds on esophageal mucosa. Scand J. Gastroenterol. Suppl., 67: 119121. PMID: 6941387

Lagergren, J., R. Bergstrom, A. Lindgren and O. Nyren, 1999. Symptomatic gastroesophageal reflux as a risk factor for esophageal adenocarcinoma. N. Engl. J. Med., 340: 825-831. DOI: 10.1056/NEJM199903183401101

Lillemoe, K.D., L.F. Johnson and J.W. Harmon, 1982. Role of the components of the gastroduodenal contents in experimental acid esophagitis. Surgery, 92: 276-284. PMID: 6808683

Lillemoe, K.D., L.F. Johnson and J.W. Harmon, 1985. Taurodeoxycholate modulates the effects of pepsin and trypsin in experimental esophagitis. Surgery, 97: 662-667. PMID: 3923639

Lillemoe, K.D., T.R. Gadacz and J.W. Harmon, 1983. Bile absorption occurs during disruption of the esophageal mucosal barrier. J. Surg. Res., 35: 57-62. DOI: 10.1016/0022-4804(83)90126-9

Locke, G.R., N.J. Talley, S.L. Fett, A.R. Zinsmeister and L.J. Melton, 1997. Prevalence and Clinical Spectrum of Gastroesophageal Reflux: A population-based study in Olmsted County, Minnesota. Gastroenterology, 112: 1448-1456. DOI: 10.1016/S0016-5085(97)70025-8

Lorusso, D., F. Pezzolla, C. Montesani, P. Giorgio and M.L. Caruso et al., 1990. Duodenogastric reflux and gastric histology after cholecystectomy with or without sphincteroplasty. Br. J. Surg., 77: 13051307. DOI: $10.1002 /$ bjs. 1800771136 
Lujan-Mompean, J.A., R. Robles-Campos, P. ParrillaParicio, R. Liron-Ruiz and J.A. Torralba-Martinez et al., 1993. Duodenogastric reflux in patients with biliary lithiasis before and after cholecystectomy. Surg. Gynecol. Obstet., 176: 116-118. PMID: 8421797

Mahmoud, N.N., A.J. Dannenberg, R.T. Bilinski, J.R. Mestre and A. Chadburn et al., 1999. Administration of an unconjugated bile acid increases duodenal tumors in a murine model of familial adenomatous polyposis. Carcinogenesis, 20: 299-303. DOI: 10.1093/carcin/20.2.299

Mainie, I., R. Tutuian, A. Agrawal, D. Adams and D.O. Castell, 2006. Combined multichannel intraluminal impedance-pH monitoring to select patients with persistent gastro-oesophageal reflux for laparoscopic Nissen fundoplication. Br. J. Surgery, 93: 14831487. DOI: $10.1002 /$ bjs.5493

Manifold, D.K., A. Anggiansah and W.J. Owen, 2000a. Effect of cholecystectomy on gastroesophageal and duodenogastric reflux. Am. J. Gastroenterol., 95: 2746-2750. PMID: 11051343

Manifold, D.K., R.E. Marshall, A. Anggiansah and W.J. Owen, 2000b. Effect of omeprazole on antral duodenogastric reflux in Barrett oesophagus. Scand J. Gastroenterol., 35: 796-801. DOI: 10.1080/003655200750023147

Marshall, R.E., A. Anggiansah and W.J. Owen, 1997. Bile in the oesophagus: Clinical relevance and ambulatory detection. Br. J. Surg., 84: 21-28. DOI: 10.1002/bjs. 1800840108

Marshall, R.E., A. Anggiansah, D.K. Manifold, W.A. Owen and W.J. Owen, 1998. Effect of omeprazole $20 \mathrm{mg}$ twice daily on duodenogastric and gastrooesophageal bile reflux in Barrett's oesophagus. Gut, 43: 603-606. DOI: 10.1136/gut.43.5.603

Marshall, R.E., A. Anggiansah, W.A. Owen, D.K. Manifold and W.J. Owen, 2001. The extent of duodenogastric reflux in gastro-oesophageal reflux disease. Eur. J. Gastroenterol. Hepatol., 13: 5-10. DOI: 10.1097/00042737-200101000-00002

Mason, R.C., P.R. Taylor, M.I. Filipe and I. McColl, 1988. Pancreaticoduodenal secretions and the genesis of gastric stump carcinoma in the rat. Gut, 29: 830-834. DOI: 10.1136/gut.29.6.830

Mattioli, S., V. Pilotti, V. Felice, A. Lazzari and R. Zannoli et al., 1990. Ambulatory 24-hr pH monitoring of esophagus, fundus and antrum. A new technique for simultaneous study of gastroesophageal and duodenogastric reflux. Dig. Dis. Sci., 35: 929-938. DOI: 10.1007/BF01537239
McDonnell, C.O., I. Bailey, T. Stumpf, T.N. Walsh and C.D. Johnson, 2002. The effect of cholecystectomy on plasma cholecystokinin. Am. J. Gastroenterol., 97: 2189-2192. DOI: $10.1111 /$ j.15720241.2002.05971.x

Melo, L.L., C.D. Kruel, L.M. Kliemann, L.T. Cavazzola and B.L Rda et al., 1999. Influence of surgically induced gastric and gastroduodenal content reflux on esophageal carcinogenesis-experimental model in Wistar female rats. Dis. Esophagus, 12: 106-115. DOI: $10.1046 /$ j.1442-2050.1999.00011.x

Menges, M., M. Muller and M. Zeitz, 2001. Increased acid and bile reflux in Barrett's esophagus compared to reflux esophagitis and effect of proton pump inhibitor therapy. Am. J. Gastroenterol., 96: 331337. DOI: 10.1111/j.1572-0241.2001.03515.x

Miwa, K., H. Hasegawa, T. Fujimura, H. Matsumoto and R. Miyata et al., 1992b. Duodenal reflux through the pylorus induces gastric adenocarcinoma in the rat. Carcinogenesis, 13: 2313-2316. DOI: 10.1093/carcin/13.12.2313

Miwa, K., T. Fujimura, H. Hasegawa, T. Kosaka and R. Miyata et al., 1992a. Is bile or are pancreaticoduodenal secretions related to gastric carcinogenesis in rats with reflux through the pylorus. J. Cancer Res. Clin Oncol 118: 570-574. DOI: 10.1007/BF01211798

Miwa, K., T. Hattori and I. Miyazaki, 1995. Duodenogastric reflux and foregut carcinogenesis. Cancer, 75: 1426-1432. PMID: 7889469

Moore, K.H., P. Barry, J. Burn and G. Falk, 2001. Adenocarcinoma of the rat esophagus in the presence of a proton pump inhibitor: A pilot study. Dis. Esophagus, 14: 17-22. DOI: 10.1111/j.14422050.2001.00145.x

Mud, H.J., S.E. Kranendonk, H. Obertop, H. Van Houten and D.L. Westbroek, 1982. Active trypsin and reflux oesophagitis: An experimental study in rats. Br. J. Surg., 69: 269-272. DOI: 10.1002/bjs.1800690513

Nair, P.P., J.G. Banwell, S.L. Gorbach, C. Lilis and A. Alcaraz, 1970. Tropical sprue and malnutrition in West Bengal. 3. Biochemical characteristics of bile salts in the small intestine. Am. J. Clin. Nutr., 23: 1569-1578. PMID: 5481891

Nakama, A., S. Hirota, T. Okazaki, K. Nagano and S. Kawano et al., 1998. Disturbed pyloric motility in Ws/Ws mutant rats due to deficiency of c-kitexpressing interstitial cells of Cajal. Pathol. Int., 48: 843-849. DOI: 10.1111/j.1440-1827.1998.tb03850.x

Nasr, A.O., S. Conlon, C. Gang, A. Ireland and E. Leen et al., 2006. Does acid suppression induce the carcinogenic effect of bile on the oesophagus in an animal model. 
Nehra, D., P. Howell, C.P. Williams, J.K. Pye and J. Beynon, 1999. Toxic bile acids in gastrooesophageal reflux disease: Influence of gastric acidity. Gut, 44: 598-602. DOI: 10.1136/gut.44.5.598

Netzer, P., A. Gut, R. Brundler, C. Gaia and F. Halter et al., 2001. Influence of pantoprazole on oesophageal motility and bile and acid reflux in patients with oesophagitis. Aliment. Pharmacol. Ther., 15: 13751384. DOI: $10.1046 / \mathrm{j} .1365-2036.2001 .01069 . x$

Nielsen, J., 2005. pKa calculation. WI pKa calcualtion package. University College Dubiln, Dublin.

Nishijima, K., K. Miwa, T. Miyashita, S. Kinami and I. Ninomiya et al., 2004. Impact of the biliary diversion procedure on carcinogenesis in Barrett's esophagus surgically induced by duodenoesophageal reflux in rats. Ann. Surg., 240: 57-67. DOI: 10.1097/01.sla.0000130850.31178.8c

Oberg, S., M.P. Ritter, P.F. Crookes, M. Fein and R.J. Mason et al., 1998. Gastroesophageal reflux disease and mucosal injury with emphasis on short-segment Barrett's esophagus and duodenogastroesophageal reflux. J. Gastrointest Surg., 2: 547-553. DOI: $10.1016 / \mathrm{S} 1091-255 \mathrm{X}(98) 80055-3$

Okholm, M., H. Sorensen, L. Wallin and S. Boesby, 1999. Bile reflux into the esophagus. Bilitec 2000 measurements in normal subjects and in patients after Nissen fundoplication. Scand J. Gastroenterol., 34: 653-657. DOI: /10.1080/003655299750025831

Orel, R. and S. Markovic, 2003. Bile in the esophagus: A factor in the pathogenesis of reflux esophagitis in children. J. Pediatr. Gastroenterol. Nutr., 36: 266273. DOI: 10.1097/00005176-200302000-00020

Orlando, R.C. and E.M. Bozymski, 1973. Heartburn in pernicious anemia--a consequence of bile reflux. N. Engl. J. Med., 289: 522-523. DOI: 10.1056/NEJM197309062891008

Osugi, H., M. Higashino, S. Kaseno, N. Takada and M. Takemura et al., 2002. Ambulatory intraesophageal bilirubin monitoring in Japanese patients with gastroesophageal reflux. J. Gastroenterol., 37: 697702. DOI: $10.1007 / \mathrm{s} 005350200114$

Ouatu-Lascar, R. and G. Triadafilopoulos, 1998. Oesophageal mucosal diseases in the elderly. Drugs Aging, 12: 261-276. DOI: 10.2165/00002512199812040-00002

Owen, R.W., M.H. Thompson and M.J. Hill, 1984. Analysis of metabolic profiles of steroids in faeces of healthy subjects undergoing chenodeoxycholic acid treatment by liquid-gel chromatography and gas-liquid chromatography-mass spectrometry. J. Steroid. Biochem., 21: 593-600. DOI: 10.1016/0022-4731(84)90336-4
Palmer, E.D., 2002. Subacute eroive ("peptic") esophagitis associated with achlorhydria. N. Engl. J. Med., 262: 927-929. DOI: 10.1056/NEJM196005052621807

Pellegrini, C.A., T.R. DeMeester, J.A. Wernly, L.F. Johnson and D.B. Skinner, 1978. Alkaline gastroesophageal reflux. Am. J. Surg., 135: 177-184. DOI: 0.1016/0002-9610(78)90093-4

Pera, M., V.F. Trastek, H.A. Carpenter, P.L. Fernandez and A. Cardesa et al., 1993. Influence of pancreatic and biliary reflux on the development of esophageal carcinoma. Ann. Thorac Surg., 55: 1386-1392. DOI: 10.1016/0003-4975(93)91077-Z

Popesco, A., G. Benga, D. Coman and V. Pop, 1966. A comparative study of serum and biliary free amino acids in liver diseases. (A method of exploration of amino acid metabolism). Rev. Int. Hepatol., 16: 1419-28. PMID: 5959052

Richter, J.E., 2000. Importance of bile reflux in Barrett's esophagus. Dig. Dis., 18: 208-216. DOI: 10.1159/000051401

Richter, J.E., D.R. Campbell, P.J. Kahrilas, B. Huang and C. Fludas, 2000. Lansoprazole compared with ranitidine for the treatment of nonerosive gastroesophageal reflux disease. Arch. Int. Med., 160: 1803-1809. DOI: 10.1001/archinte.160.12.1803

Roda, A., A.F. Hofmann and K.J. Mysels, 1983. The influence of bile salt structure on self-association in aqueous solutions. J. Biol. Chem., 258: 6362-6370. PMID: 6853487

Roda, A., A.M. Gioacchini, A.C. Manetta, C. Cerre and M. Montagnani et al., 1995. Bile acids: Physicochemical properties, function and activity. Ital. J. Gastroenterol., 27: 327-331. PMID: 8562999

Rothwell, J.F., P. Lawlor, P.J. Byrne, T.N. Walsh and T.P. Hennessy, 1997. Cholecystectomy-induced gastroesophageal reflux: Is it reduced by the laparoscopic approach? Am. J. Gastroenterol., 92: 1351-1354. PMID: 9260805

Salo, J. and E. Kivilaakso, 1982. Role of luminal H+ in the pathogenesis of experimental esophagitis. Surgery, 92: 61-68. PMID: 6806928

Salo, J.A. and E. Kivilaakso, 1984a. Contribution of trypsin and cholate to the pathogenesis of experimental alkaline reflux esophagitis. Scand. J. Gastroenterol., 19: 875-881.

Salo, J.A. and E. Kivilaakso, 1984b. Effect of cimetidine on HCl-taurocholate-induced esophageal mucosal injury. Acta Chir. Scand., 150: 647-652. PMID: 6532036

Sandvik, A.K. and T.B. Halvorsen, 1988. Barrett's esophagus after total gastrectomy. J. Clin. Gastroenterol., 10: 587-588. DOI: 10.1097/00004836-198810000-00023 
Scarpignato, C., I. Pelosini and S. Contini, 2006. How Can Reduction of Duodenogastroesophageal Reflux following Medical Acid Suppresion by Proton Pump Inhibitors be Explained? In: The Duodenogastroesophageal Reflux: From the Dudenum to the Trachea 125 Questions-125 Answers, Giuli, R., J.M. Collard, C. Scarpignato and J.E Richter, (Eds.), John Libbey Eurotext Limited, Paris, ISBN-10: 2742006478, pp: 291-298.

Schindlbeck, N.E., C. Heinrich, F. Stellaard, G. Paumgartner, S.A. Muller-Lissner, 1987. Healthy controls have as much bile reflux as gastric ulcer patients. Gut, 28: 1577-1583. PMID: 3428684

Scholmerich, J., M.S. Becher, K. Schmidt, R. Schubert and B. Kremer et al., 1984. Influence of hydroxylation and conjugation of bile salts on their membrane-damaging properties--studies on isolated hepatocytes and lipid membrane vesicles. Hepatology, 4: 661-666. DOI: 10.1002/hep.1840040416

Schweitzer, E.J. and J.W. Harmon, 1986. Experimental gastritis: Are the detergents on or in the mucosa. Am. J. Physiol., 251: G870- G872. PMID: 3789154

Schweitzer, E.J., B.L. Bass, S. Batzri and J.W. Harmon, 1986. Bile acid accumulation by rabbit esophageal mucosa. Dig. Dis. Sci., 31: 1105-1113. DOI: 10.1007/BF01300265

Schweitzer, E.J., J.W. Harmon, B.L. Bass and S. Batzri, 1984. Bile acid efflux precedes mucosal barrier disruption in the rabbit esophagus. Am. J. Physiol., 247: G480- G485. PMID: 6496738

Sears, R.J., G.L. Champion and J.E. Richter, 1995. Characteristics of distal partial gastrectomy patients with esophageal symptoms of duodenogastric reflux. Am. J. Gastroenterol., 90: 211-215. PMID: 7847287

Segalin, A., P. Granelli, L. Bonavina, C. Siardi and L. Mazzoleni et al., 1994. Self-expanding esophageal prosthesis. Effective palliation for inoperable carcinoma of the cervical esophagus. Surg. Endosc., 8: 1343-1345. PMID: 7530383

Shay, S., R. Tutuian, D. Sifrim, M. Vela and J. Wise et al., 2004. Twenty-four hour ambulatory simultaneous impedance and $\mathrm{pH}$ monitoring: a multicenter report of normal values from 60 healthy volunteers. Am. J. Gastroenterol., 99: 1037-1043. DOI: $10.1111 / \mathrm{j} .1572-0241.2004 .04172 . \mathrm{x}$

Sifrim, D., D. Castell, J. Dent and P.J. Kahrilas, 2004. Gastro-oesophageal reflux monitoring: Review and consensus report on detection and definitions of acid, non-acid and gas reflux. Gut, 53: 1024-1031. DOI: $10.1136 /$ gut.2003.033290
Smallwood, R.A. and N.E. Hoffman, 1976. Bile acid structure and biliary secretion of cholesterol and phospholipid in the cat. Gastroenterology, 71: 10641066. PMID: 992268

Sonnenberg, A., 2004. Review article: Trials on reflux disease--the role of acid secretion and inhibition. Aliment. Pharmacol. Ther., 5: 2-8. DOI: 10.1111/j.1365-2036.2004.02131.x

Spechler, S.J., 1996. Barrett's esophagus. Semin. Gastrointest. Dis., 7: 51-60. PMID: 8705259

Stamp, D.H., 2002. Three hypotheses linking bile to carcinogenesis in the gastrointestinal tract: Certain bile salts have properties that may be used to complement chemotherapy. Med. Hypotheses, 59: 398-405. DOI: 10.1016/S0306-9877(02)00125-1

Stein, H.J., H. Feussner, W. Kauer, T.R. DeMeester and J.R. Siewert, 1994a. Alkaline gastroesophageal reflux: Assessment by ambulatory esophageal aspiration and $\mathrm{pH}$ monitoring. Am. J. Surg., 167: 163-168. DOI: 10.1016/0002-9610(94)90068-X

Stein, H.J., O. Korn and D. Liebermann-Meffert, 1995. Manometric vector volume analysis to assess lower esophageal sphincter function. Ann. Chir. Gynaecol., 84: 151-518. PMID: 7574373

Stein, H.J., T.R. DeMeester, J.H. Peters and K.H. Fuchs, 1994b. Technique, indications and clinical use of ambulatory $24 \mathrm{~h}$ gastric $\mathrm{pH}$ monitoring in a surgical practice. Surgery, 116: 758-766. PMID: 7940176

Stein, H.J., W.K. Kauer, H. Feussner and J.R. Siewert, 1998. Bile reflux in benign and malignant Barrett's esophagus: effect of medical acid suppression and nissen fundoplication. J. Gastrointest. Surg., 2: 333341. DOI: $10.1016 / \mathrm{S} 1091-255 X(98) 80072-3$

Stein, H.J., W.K. Kauer, H. Feussner and J.R. Siewert, 1999. Bile acids as components of the duodenogastric refluxate: detection, relationship to bilirubin, mechanism of injury and clinical relevance. Hepatogastroenterology, 46: 66-73. PMID: 10228767

Stern, A.I., D.L. Hogan and J.I. Isenberg, 1984. Effect of sodium taurocholate on the human gastric mucosa at acid and neutral pH's. Gastroenterology, 87: 12721276. PMID: 6489697

Stevens, I.W., Z. Lawrence and Y. Elitsur, 2001. Diagnosis and treatment of Helicobacter pylori infection in children: A survey of WV primary care physicians. W V Med. J., 97: 257-259. PMID: 11761653

Stipa, F., H.J. Stein, H. Feussner, S. Kraemer and J.R. Siewert, 1997. Assessment of non-acid esophageal reflux: comparison between long-term reflux aspiration test and fiberoptic bilirubin monitoring. Dis. Esophagus, 10: 24-28. PMID: 9079269 
Theisen, J., J.H. Peters and H.J. Stein, 2003. Experimental evidence for mutagenic potential of duodenogastric juice on Barrett's esophagus. World J. Surg., 27: 1018-1020. DOI: 10.1007/s00268-0037055-Z

Theisen, J., J.H. Peters, M. Fein, M. Hughes and J.A. Hagen et al., 2005. The mutagenic potential of duodenoesophageal reflux. Ann. Surg., 241: 63-68. PMID: 15621992

Tibbling, G.L., L. Blackadder, T. Franzen and E. Kullman, 2002. Gastric bile monitoring: An in vivo and in vitro study of Bilitec reliability. Scand J. Gastroenterol., 37: 1334-1337. DOI: $10.1080 / 003655202761020632$

Triadafilopoulos, G., 2006. Medical Treatment of Gastroesophageal Reflux Disease. In: The Duodenogastroesophageal Reflux: From the Dudenum to the Trachea 125 Questions-125 Answers, Giuli, R., J.M. Collard, C. Scarpignato and J.E Richter, (Eds.), John Libbey Eurotext Limited, Paris, ISBN-10: 2742006478, pp: 308-317.

Turjman, N. and P.P. Nair, 1981. Nature of tissue-bound lithocholic acid and its implications in the role of bile acids in carcinogenesis. Cancer Res., 41: 37613763. PMID: 7020935

Tutuian, R. and D.O. Castell, 2006. Review article: Complete gastro-oesophageal reflux monitoringcombined $\mathrm{pH}$ and impedance. Alimentary Pharmacol. Therapeutics, 24: 27-37. DOI: 10.1111/j.1365-2036.2006.03039.x

Vaezi, M.F. and J.E. Richter, 1996. Role of acid and duodenogastroesophageal reflux in gastroesophageal reflux disease. Gastroenterology, 111: 1192-1199. DOI: 10.1053/gast.1996.v111.pm8898632

Vaezi, M.F., 1995. Richter JE. Synergism of acid and duodenogastroesophageal reflux in complicated Barrett's esophagus. Surgery, 117: 699-704. DOI: 10.1016/S0039-6060(95)80015-8

Vaezi, M.F., S. Singh and J.E. Richter, 1995. Role of acid and duodenogastric reflux in esophageal mucosal injury: A review of animal and human studies. Gastroenterology, 108: 1897-1907. DOI: 10.1016/0016-5085(95)90156-6

Vela, M.F., L. Camacho-Lobato, R. Srinivasan, R. Tutuian and P.O. Katz et al., 2001. Simultaneous intraesophageal impedance and $\mathrm{pH}$ measurement of acid and nonacid gastroesophageal reflux: Effect of omeprazole. Gastroenterology, 120: 1599-1606. DOI: $10.1053 /$ gast.2001.24840
Waring, J.P., J. Legrand, A. Chinichian and R.A. Sanowski, 1990. Duodenogastric reflux in patients with Barrett's esophagus. Dig. Dis. Sci., 35: 759762. DOI: 10.1007/BF01540180

Wetscher, G.J., K. Glaser, M. Gadenstaetter, C. Profanter and R.A. Hinder, 1999b. The effect of medical therapy and antireflux surgery on dysphagia in patients with gastroesophageal reflux disease without esophageal stricture. Am. J. Surg., 177: 189192. DOI: 10.1016/S0002-9610(99)00011-2

Wetscher, G.J., R.A. Hinder, T. Smyrk, G. Perdikis and T.E. Adrian et al., 1999a. Gastric acid blockade with omeprazole promotes gastric carcinogenesis induced by duodenogastric reflux. Dig. Dis. Sci., 44: 11321135. DOI: 10.1023/A:1026615905170

Wilmer, A., J.F.E. Tack, H. Dits, S. Vanderschueren and A. Gevers et al., 1996. Duodenogastroesophageal reflux and esophageal mucosal injury in mechanically ventilated patients. Gastroenterology, 116: 1293-1299. DOI: 10.1016/S00165085(99)70492-0

Winters, C, Jr., T.J. Spurling, S.J. Chobanian, D.J. Curtis and R.L. Esposito et al., 1987. Barrett's esophagus. A prevalent, occult complication of gastroesophageal reflux disease. Gastroenterology, 92: 118-124. PMID: 3781178

Wurm, P. and J.D. Caestecker, 2003. Pharmacotherapy for chronic gastro-oesophageal reflux disease and Barrett's oesophagus. Expert Opin. Pharmacother., 4: 1049-1061. DOI: 10.1517/14656566.4.7.1049

Yumiba, T., H. Kawahara, K. Nishikawa, Y. Inoue and T. Ito et al., 2002. Impact of esophageal bile exposure on the genesis of reflux esophagitis in the absence of gastric acid after total gastrectomy. Am. J. Gastroenterol., 97: 1647-1652. DOI: 10.1111/j.1572-0241.2002.05822.x

Zerbib, F., S. Roman, A. Ropert, S.B. des Varannes and P. Pouderoux et al., 2006. Esophageal pHImpedance Monitoring and Symptom Analysis in GERD: A Study in Patients off and on Therapy. Am. J. Gastroenterol., 101: 1956-1963. DOI: 10.1111/j.1572-0241.2006.00711.x 